\title{
Sistem Kontrol Robot Arm 5 DOF Berbasis Pengenalan Pola Suara Menggunakan Mel-Frequency Cepstrum Coefficients (MFCC) dan Adaptive Neuro-Fuzzy Inference System (ANFIS)
}

\author{
W.S. Mada Sanjaya ${ }^{12}$, Dyah Anggraeni ${ }^{12}$ \\ ${ }^{1}$ Program Studi Fisika, Fakultas Sains dan Teknologi, Universitas Islam Negeri \\ Sunan Gunung Djati Bandung, Jl. AH Nasution 105 Cibiru Bandung 40614, \\ Indonesia \\ ${ }^{2}$ Bolabot Techno Robotic Institue, CV. Sanjaya Star Group, Komp. Permata Biru \\ Blok AH No 75A Cibiru-Cinunuk Bandung 40624, Indonesia \\ *E-mail:madasws@gmail.com (Mada Sanjaya), \\ Telp: $+62-81227759579$
}

\begin{abstract}
ABSTRAK
Telah dilakukan penelitian yang menggambarkan implementasi pengenalan pola suara untuk mengontrol gerak robot arm 5 DoF dalam mengambil dan menyimpan benda. Dalam penelitian ini metode yang digunakan adalah Mel-Frequency Cepstrum Coefficients (MFCC) dan Adaptive Neuro-Fuzzy Inferense System (ANFIS). Metode MFCC digunakan untuk ekstraksi ciri sinyal suara, sedangkan ANFIS digunakan sebagai metode pembelajaran untuk pengenalan pola suara. Pada proses pembelajaran ANFIS data latih yang digunakan sebanyak 6 ciri. Data suara terlatih dan data suara tak terlatih digunakan untuk pengujian sistem pengenalan pola suara. Hasil pengujian menunjukkan tingkat keberhasilan, untuk data suara terlatih sebesar $87,77 \%$ dan data
\end{abstract}


tak terlatih sebesar 78,53\%. Sistem pengenalan pola suara ini telah diaplikasikan dengan baik untuk mengerakan robot arm 5 DoF berbasis mikrokontroler Arduino.

\title{
Kata Kunci : Pengenalan suara; ANFIS; robot arm Mel-Frequency Cepstrum Coefficients
}

\begin{abstract}
Have been implemented of sound pattern recognition to control 5 DoF of Arm Robot to pick and place an object. In this research used Mel-Frequency Cepstrum Coefficients (MFCC) and Adaptive Neuro-Fuzzy Interferense System (ANFIS) methods. MFCC method used for features extraction of sound signal, meanwhile ANFIS used to learn sound pattern recognition. On ANFIS method data learning use 6 features. Trained and not trained data used to examine the system of sound pattern identification. The result show the succesfull level, for trained data $87.77 \%$ and for not trained data $78.53 \%$. Sound pattern identification system was appliedto controlled 5 DoF arm robot based Arduino microcontroller.
\end{abstract}

Keywords : Sound identification; ANFIS; arm robot; Mel-Frequency Cepstrum Coefficients

\section{Pendahuluan}

Sistem otomatisasi pada bidang robotika merupakan sistem yang dapat memudahkan pekerjaaan manusia.

Sistem kendali dengan menggunakan suara merupakan alternatif yang mudah dan efektif khususnya untuk pengguna yang memiliki keterbatasan fisik.
Penerapan sistem kendali menggunakan suara tidak mudah dilakukan oleh mesin, sehingga dibutuhkan metode pembelajaran pada mesin untuk dapat mengekstraksi dan mengenali ciri atau pola suara dengan mempelajari ciri-ciri sebelumnya.

Metode untuk mengekstrak ciri sinyal suara diantaranya menggunakan 
metode Linear Predictive Coding [1],

[2] dan Mel-Frequency Cepstrum 2. Landasan Teori

Coefficients [3] - [4] yang telah

2.1. Metode MFCC

diaplikasikan pada beberapa bidang

MFCC merupakan cara yang paling diantaranya; pengenal pembicara [5] [6], mendiagnosis suatu penyakit [2], [7] , kontrol robot [8], [9] , kontrol motor DC [10] , control robot arm [11] [12], smart home [13], biomatriks [14], kontrol otomatis kursi roda [15] dan lainnya [16]. Untuk metode pembelajaran dan pengklasifikasian pola suara, telah banyak peneliti yang menggunakan metode Neuro-Fuzzy [13], Artificial Neural Networks [17], [18] , dan metode soft computing lainnya [6], [19].

Dalam penelitian ini dibahas pengujian sistem ekstraksi ciri sinyal suara menggunakan Mel-Frequency Cepstrum Coefficients (MFCC) dan metode belajar serta klasifikasi pola suara menggunakan metode Adaptive Neuro-Fuzzy Inferense System (ANFIS). Terakhir, dalam penelitian ini juga dilakukan implementasi sistem pengenalan pola suara untuk sistem kontrol robot arm pemindah barang menggunakan mikrokontroler Arduino.

sering digunakan pada berbagai bidang area pemrosesan suara, karena dianggap cukup baik dalam merepresentasikan sinyal. Cara kerja MFCC didasarkan pada perbedaan frekuensi yang dapat ditangkap oleh telinga manusia sehingga mampu merepresentasikan sinyal suara sebagaimana manusia merepresentasikannya.

\subsection{Preemphasis}

Dalam proses pengolahan sinyal wicara pre emphasis filter diperlukan setelah proses sampling. Tujuan dari pemfilteran ini adalah untuk mendapatkan bentuk spectral frekuensi sinyal wicara yang lebih halus. Dimana bentuk spectral yang relatif bernilai tinggi untuk daerah rendah dan cenderung turun secara tajam untuk daerah fekuensi diatas $2000 \mathrm{~Hz}$. Filter pre-emphasis didasari oleh hubungan input/output dalam domain waktu yang

154 | Copyright $@$ 2016, Wahana Fisika 
dinyatakan dalam persamaan

berikut: $y(n)=x(n)-a x(n-1)(1)$

dimana $a$ merupakan konstanta filter

pre-emhasis, biasanya bernilai $0.9<a$

$<1.0$.

\subsection{Frame Blocking}

Pada proses ini, sinyal suara disegmentasi menjadi beberapa frame yang saling tumpang tindih (overlap).

Hal ini dilakukan agar tidak ada sedikitpun sinyal yang hilang (deletion). Proses ini akan berlanjut sampai seluruh sinyal sudah masuk ke dalam satu atau lebih frame.

\subsection{Windowing}

Sinyal analog yang sudah diubah menjadi sinyal digital dibaca frame demi frame dan pada setiap frame-nya dilakukan windowing dengan fungsi window tertentu. Proses windowing bertujuan untuk meminimalisasi ketidakberlanjutan sinyal pada awal dan akhir setiap frame. Jika kita definisikan window sebagai $w(n), 0 \leq n$ $\leq N-1$, dimana $N$ adalah jumlah sampel pada setiap frame-nya, maka hasil dari windowing adalah sinyal: $y_{1}(n)=x_{1}(n) w(n), 0 \leq n \leq N-$

dimana $w(n)$ biasanya menggunakan window Hamming yang memiliki bentuk:

$w(n)=0.54-0.46 \cdot \cos \left(\frac{2 \pi n}{N-1}\right), 0 \leq$

$n \leq N-1$

\subsection{Fast Fourier Transform (FFT)}

FFT merupakan fast algorithm dari Discrete Fourier Transform (DFT) yang berguna untuk mengonversi setiap frame dengan $N$ sampel dari domain waktu menjadi domain frekuensi, sebagaimana didefinisikan sebagai berikut $X_{n}=\sum_{k=0}^{N-1} x_{k} e^{-2 \pi j k n / N}$

dimana $n=0,1,2, \ldots, N-1 \quad$ dan $j=\sqrt{-1}$.

Hasil dari tahapan ini biasanya disebut dengan spectrum atau periodogram.

\subsection{Mel-Frequency Wrapping}

Persepsi sistem pendengaran manusia terhadap frekuensi sinyal suara tidak dapat diukur dalam skala linear. Untuk setiap nada dengan frekuensi aktual, $f$, diukur dalam $\mathrm{Hz}$, sebuah subjective pitch diukur dalam sebuah skala yang 
disebut "mel". Skala mel-frequency ialah sebuah frekuensi rendah yang bersifat linear di bawah $1000 \mathrm{~Hz}$ dan sebuah frekuensi tinggi yang bersifat logaritmik di atas $1000 \mathrm{~Hz}$. Persamaan berikut menunjukkan hubungan skala mel dengan frekuensi dalam $\mathrm{Hz}$ : $F_{m e l}=$ $\begin{cases}2595 * \log _{10}\left(1+\frac{F_{H Z}}{700}\right), & F_{H Z}>1000 \\ F_{H Z}, & F_{H Z}<1000\end{cases}$ (5)

Proses wrapping terhadap sinyal dalam domain frekuensi dilakukan menggunakan persamaan berikut:

$X_{i}=\log _{10}\left(\sum_{k=0}^{N-1}|X(k)| H_{i}(k)\right)$

dimana $i=1,2,3, \ldots, M \quad(M$ adalah jumlah filter segitiga) dan $H_{i}(k)$ adalah nilai filter segitiga ke- $i$ untuk frekuensi akustik sebesar $k$.

\subsection{Cepstrum}

Pada tahap ini akan dikonversi mel- spectrum ke dalam domain waktu dengan menggunakan Discrete Cosine Transform (DCT). Hasilnya disebut dengan mel-frequency cepstrum coefficient (MFCC). Berikut adalah persamaan yang digunakan dalam transformasi cosinus: $\quad C_{j}=$ $\sum_{i=1}^{M} X_{i} \cos \left(j(i-1) / 2 \frac{\pi}{M}\right)$

dimana $j=1,2,3, \ldots, K(K=$ jumlah koefisien yang diinginkan) dan $M$ adalah jumlah filter.

\subsection{Adaptive Neuro Fuzzy Inferense System (ANFIS)}

Neuro-fuzzy adalah gabungan dari dua sistem yaitu sistem logika fuzzy dan jaringan syaraf tiruan. Sistem neurofuzzy berdasar pada sistem inferensi fuzzy yang dilatih menggunakan algoritma pembelajaran yang diturunkan dari sistem jaringan syaraf tiruan.

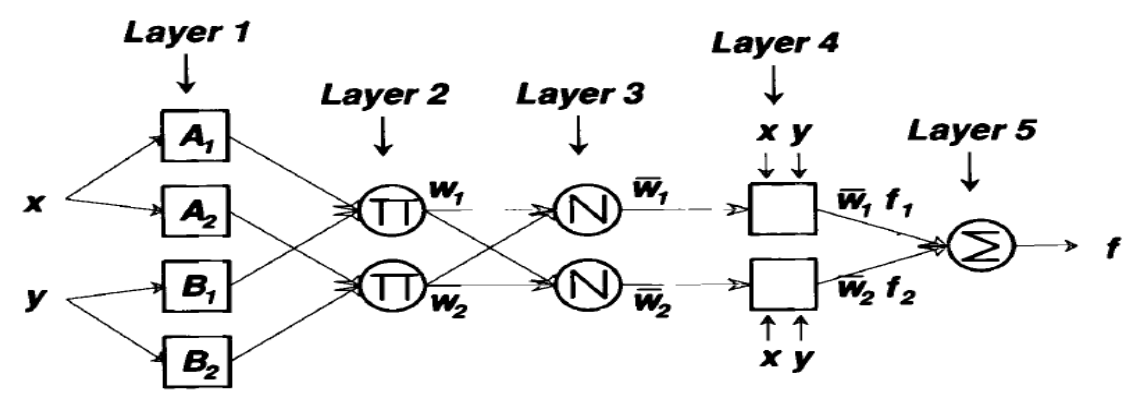

Gambar 5. Contoh struktur ANFIS Roger Jang [20] 
Salah satu bentuk struktur yang sudah sangat dikenal adalah seperti terlihat pada Gambar 5 yang merupakan struktur ANFIS. Dalam struktur ini, sistem inferensi fuzzy yang diterapkan adalah inferensi fuzzy model TakagiSugeno-Kang.

\section{Lapisan 1: Proses Fuzzyfication}

Output dari node $i$ pada layer 1 dinotasikan sebagai $O_{1, i}$ bersifat adaptif:

$O_{1, i}=\mu_{A i}(x), \quad i=1,2$

$O_{1, i}=\mu_{B i}(y), \quad i=1,2$

dimana $x$ dan $y$ adalah nilai-nilai input untuk node tersebut dan $A_{i}$ dan $B_{i}$ adalah himpunan fuzzy. Jadi, masingmasing node pada layer 1 berfungsi membangkitkan derajat keanggotaan.

\section{Lapisan 2: Lapisan Product}

Dinotasikan dengan $\pi$. Setiap node pada layer ini berfungsi untuk menghitung kekuatan aktivasi (firing strength) pada setiap rule sebagai product dari semua input yang masuk atau sebagai operator $t$-norm (triangular norm): $\quad O_{2, i}=w_{i}=$ $\mu_{A i}(x) \Delta \mu_{B i}(y), \quad i=1,2$
$w_{1}=\mu_{A 1}(x) A N D \mu_{B 1}(y)$

$$
w_{2}=\mu_{A 2}(x) A N D \mu_{B 2}(y)
$$

Output pada lapisan ini bertindak sebagai fungsi bobot.

\section{Lapisan 3: Lapisan Normalisasi}

Dinotasikan dengan $N$. Setiap node pada lapisan ini bersifat non-adaptif yang berfungsi hanya untuk menghitung rasio antara firing strength pada rule ke- $i$ terhadap total firing strength dari semua rule:

$O_{3, i}=\bar{w}_{i}=\frac{w_{i}}{w_{1}+w_{2}}, i=1,2$

\section{Lapisan 4: Lapisan Defuzzyfication}

Setiap node pada lapisan ini bersifat adaptif dengan fungsi:

$O_{4, i}=\bar{w}_{i} f_{i}=\bar{w}_{i}\left(p_{i} x+q_{i} y+r_{i}\right)(14)$ dimana $\bar{w}_{i}$ adalah output pada layer 3 dan $\left\{x+q_{i} y+r_{i}\right\}$ adalah himpunan parameter pada fuzzy model Sugeno orde pertama.

\section{Lapisan 5: Lapisan Total Output}

Satu node tunggal yang dilambangkan dengan $\Sigma$ pada layer ini berfungsi mengagregasikan seluruh output pada layer 4 (penjumlahan dari semua sinyal yang masuk):

$O_{5, i}=\sum_{i} \bar{w}_{i} f_{i}=\frac{\sum_{i} w_{i} f_{i}}{\sum_{i} w_{i}}$ 
Sehingga secara keseluruhan, kelima db dengan spesifikasi (impedansi 32 layer tersebut akan membangun suatu ohm at $1 \mathrm{kHz}$ sensitivitas $102 \mathrm{db} / \mathrm{mW}$ ), adaptive-networks yang secara laptop, mikrokontroler arduino, relay, fungsional ekivalen dengan fuzzy lampu AC. Kabel USB dan komputer model Sugeno orde pertama.

\section{Metodologi dan Perancangan Sistem} digunakan sebagai komunikasi data menggunakan software MATLAB Peralatan yang digunakan pada 2012. Metode penelitian secara garis penelitian yaitu michrophone $-54 \mathrm{db}+2$ besar dapat dilihat :

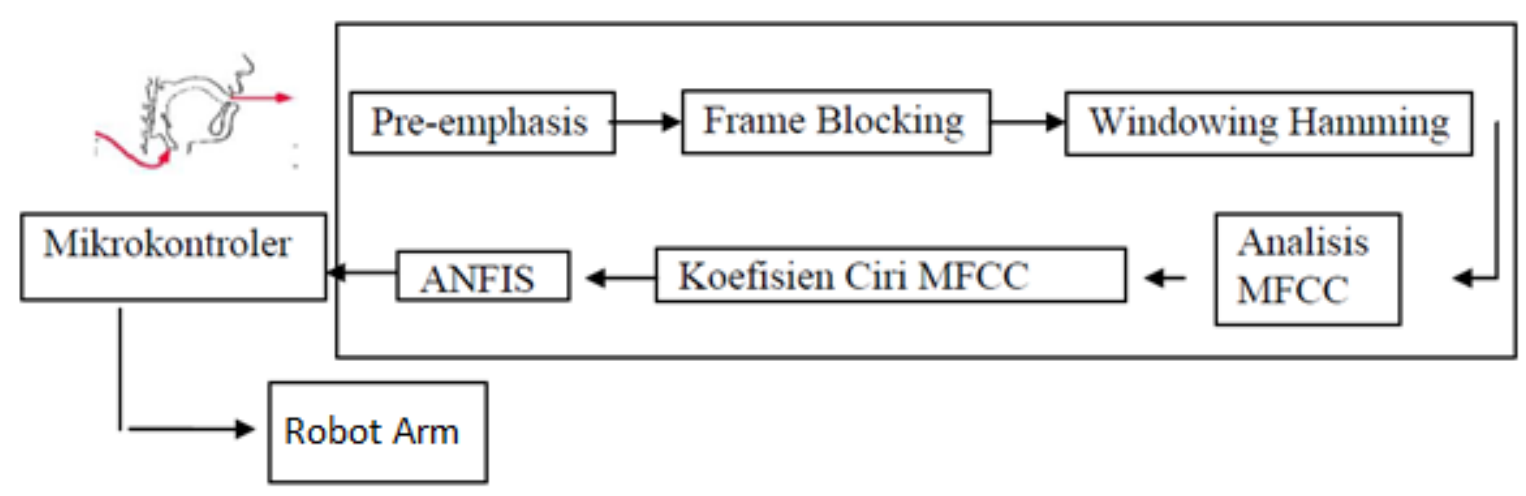

Gambar 6. Skema umum kontrol robot arm menggunakan perintah suara

Terdapat dua bagian proses dalam penelitian ini, proses pertama adalah proses pembelajaran sistem yang didalamnya meliputi proses ekstraksi ciri menggunakan MFCC dan proses belajar menggunakan ANFIS sehingga terbentuk database berupa formulasi logika fuzzy. Proses kedua adalah proses pengujian sistem yang meliputi proses ekstraksi ciri MFCC, proses pengklasifikasian data ANFIS, serta implementasi berupa komunikasi data secara serial antara komputer dengan mikrokontroler Arduino untuk menggerakan robot arm dalam memindahkan barang menggnakan perintah suara manusia.

\subsection{Perancangan Elektronik}

Berikut ini adalah skema robot lengan yang akan digunakan dalam penelitian. Robot arm ini terdiri dari lima komponen motor servo yang terkoneksi dengan mikrokontroler 


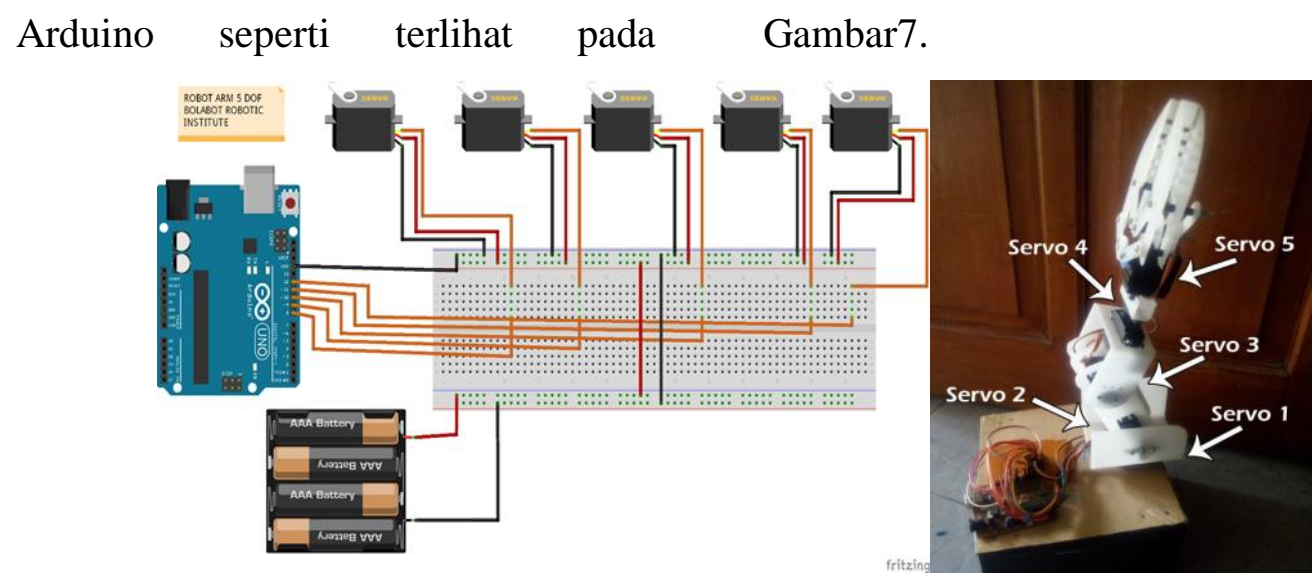

Gambar 7 Skema robot lengan dengan 5 DoF dan realisasinya

Susunan rangkaian robot terlihat seperti skema robot arm 5 DoF pada Gambar 7, tiap servo harus diberi sumber tegangan berupa baterai 5 volt dan berarus $100 \mathrm{~mA}$ (sesuai datasheet tiap servo) agar dapat beroperasi dengan baik. Ground tiap servo terkoneksi dengan ground pada mikrokontroler Arduino. Robot arm yang telah dibuat terdiri dari 5 bauh servo. Servo1 adalah servo paling bawah yang terhubung dengan pin 8 , berfungsi seperti leher (berputar secara horizontal). Servo 2 terhubung dengan pin 9 yang fungsinya sama seperti tulang lengan bawah manusia (bergrak secara vertikal). Servo 3 terhubung pada pin 10, yang berfungsi seperti pergelangan tangan manusia (bergerak vertikal). Servo 4 terhubung pada pin 11 yang berfungsi seperti pergelangan tangan (bergerak untuk memutarkan pergelangan/horizontal). Dan Servo 5 terhubung pada pin 12, berfungsi sebagai pencapit atau jari tangan sederhana untuk mengambil dan memindahkan barang.

\subsection{Perancangan Antarmuka}

Antarmuka diperlukan untuk mempermudah penggunaan dari sistem yang dibuat. Pada penelitian ini telah dibuat antarmuka menggunakan GUI MATLAB. Antarmuka yang dibuat berisi setting komunikasi serial antara mikrokontroler dan komputer, nilai koefisien ekstraksi ciri menggunakan metode MFCC, grafik time series 
sinyal suara, tombol record suara, serta suara.

output ANFIS berupa pengenalan pola

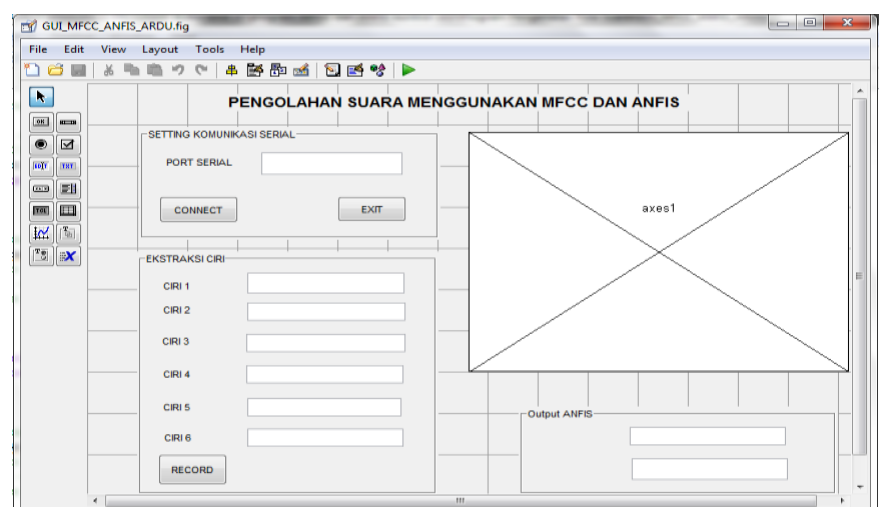

Gambar 9. Rancangan antarmuka

\section{Hasil dan Pembahasan}

4.2 Pembuatan Database Ekstraksi Ciri Menggunakan MFCC

Telah dilakukan pembuatan database 6 buah ciri /pola sinyal suara seorang responden degan mengucapkan dua buah kata "ambil" dan "simpan" dengan masing-masing $10 \quad$ kali pengulangan yang secara lengkap dapat dilihat pada tabel berikut: menggunakan metode MFCC terhadap

Tabel 1. Hasil ekstraksi ciri MFCC dan target

\begin{tabular}{|c|c|c|c|c|c|c|c|}
\hline $\begin{array}{l}\mathbf{N} \\
\mathbf{0}\end{array}$ & Ciri 1 & Ciri 2 & Ciri 3 & Ciri 4 & Ciri 5 & Ciri 6 & $\begin{array}{c}\text { Targe } \\
\mathbf{t}\end{array}$ \\
\hline \multirow[t]{2}{*}{1} & 1.02576 & 0.43096 & 0.70954 & - & - & - & \multirow{2}{*}{1} \\
\hline & 4 & 8 & 3 & 1.16757 & 0.06185 & 0.16551 & \\
\hline \multirow[t]{2}{*}{2} & \multirow{2}{*}{3.8107} & \multirow{2}{*}{1.84287} & 2.48224 & 0.71784 & 0.53090 & - & \multirow{2}{*}{1} \\
\hline & & & 7 & 2 & 6 & 0.22903 & \\
\hline \multirow[t]{2}{*}{3} & 2.99013 & \multirow{2}{*}{1.32624} & 1.37000 & 20106 & - & - & \multirow{2}{*}{1} \\
\hline & 1 & & 7 & -2.0106 & 0.51325 & 0.43964 & \\
\hline \multirow[t]{2}{*}{4} & 1.00477 & 0.26855 & 0.43315 & - & - & - & \multirow{2}{*}{1} \\
\hline & 7 & 4 & 1 & 1.36025 & 0.33288 & 0.24274 & \\
\hline \multirow[t]{2}{*}{5} & 3.64567 & 2.84625 & 2.53058 & - & - & - & \multirow{2}{*}{1} \\
\hline & 4 & 6 & 6 & 2.41073 & 0.95367 & 0.77988 & \\
\hline
\end{tabular}




\begin{tabular}{|c|c|c|c|c|c|c|c|}
\hline \multirow[t]{2}{*}{11} & 3.26284 & 0.24001 & 0.26511 & 0.23590 & \multirow{2}{*}{0.16143} & 0.06330 & \multirow{2}{*}{0} \\
\hline & 1 & 6 & 2 & 9 & & 2 & \\
\hline \multirow[t]{2}{*}{12} & 4.70256 & 0.25053 & \multirow{2}{*}{0.27633} & 0.24529 & 0.16729 & 0.06532 & \multirow{2}{*}{0} \\
\hline & 7 & 9 & & 7 & 5 & 6 & \\
\hline \multirow[t]{2}{*}{13} & 5.07718 & 3.75179 & 2.55767 & - & - & \multirow{2}{*}{-0.5631} & \multirow{2}{*}{0} \\
\hline & 7 & 2 & 1 & 3.76957 & 0.70939 & & \\
\hline \multirow[t]{2}{*}{14} & 2.31811 & 0.30361 & 0.57216 & - & - & - & \multirow{2}{*}{0} \\
\hline & 8 & 9 & 1 & 1.03665 & 0.00629 & 0.17874 & \\
\hline \multirow[t]{2}{*}{15} & \multirow{2}{*}{2.55203} & 1.02744 & \multirow{2}{*}{0.91949} & - & - & \multirow{2}{*}{-0.4275} & \multirow{2}{*}{0} \\
\hline & & 8 & & 1.39003 & 0.54355 & & \\
\hline
\end{tabular}

Dari tabel di atas terlihat bahwa kata"ambil" dan "simpan" memiliki pola ciri berbeda. Pola suara "ambil" akan di simbolkan dengan nilai target "1' sedangkan pola suara "simpan" akan disimbolkan dengan nilai target "0". Pola ini kemudian akan menjadi input untuk metode pembelajaran ANFIS yang kemudian akan menghasilkan database berupa logika Fuzzy.

\subsection{Pengujian Sistem Pengenalan luar database yang berbeda.}

\section{Pola Suara}

Hasil pengujian pengenalan ucapan menunjukkan bahwa total tingkat akurasi antara responden di dalam database sebesar $87,77 \%$ dan responden di luar database menghasilkan akurasi sebesar 78,53\%. Kesalahan-kesalahan pengenalan pola suara dapat dipengaruhi oleh aksen/intonasi kata masukan dan gangguan (noise) dari lingkungan mengingat waktu pengujian responden di dalam database dan responden di

che database yang berbeda. 
Tabel 2. Hasil pengujian pengenalan ucapan responden di dalam database.

\begin{tabular}{clccc}
\hline \multirow{2}{*}{ Pengulangan } & Kata & Target & $\begin{array}{c}\text { Output Pengenalan } \\
\text { Database }\end{array}$ & $\begin{array}{c}\text { Output } \\
\text { Pengenalan Luar } \\
\text { Database }\end{array}$ \\
\hline \multirow{2}{*}{1} & Ambil & 1 & 1.05553 & 0.883592 \\
\cline { 2 - 5 } 2 & Simpan & 0 & 0.005402 & 0.188365 \\
\hline \multirow{2}{*}{3} & Ambil & 1 & 0.904094 & 1.15296 \\
\hline \multirow{2}{*}{4} & Simpan & 0 & 0.150967 & 0.0114219 \\
\cline { 2 - 5 } & Ambil & 1 & 0.940149 & 1.23366 \\
\hline \multirow{2}{*}{5} & Simpan & 0 & 0.16039 & 0.366108 \\
\hline & Ambil & 1 & 0.778915 & 1.51449 \\
\hline & Simpan & 0 & 0.210363 & 0.0297445 \\
\hline & Ambil & 1 & 1.24385 & 0.73461 \\
\hline
\end{tabular}

Berikut adalah tampilan GUI saat dilakukan pengujian terhadap kata"ambil" dan "simpan". Dari Gambar 11 terlihat, saat kata "ambil" direcord maka sistem akan mengenali dengan output 0.811674 yang mendekati nilai “1' sehingga komputer akan mengirimkan data serial berupa karakter "1" ke mikrokontroler untuk menggerakan robot arm dalam posisi mengambil benda. Sedangkan saat kata "simpan" direcord maka sistem akan mengenali dengan output sebesar 0.490851 yang mendekati nilai "0" sehingga komputer akan mengirimkan data serial berupa karakter " 0 " ke mikrokontroler untuk menggerakan robot arm dalam posisi menyimpan benda. Sehingga secara umum alat berfungsi dengan baik 100\% karena adanya pembulatan nilai pengenalan. 


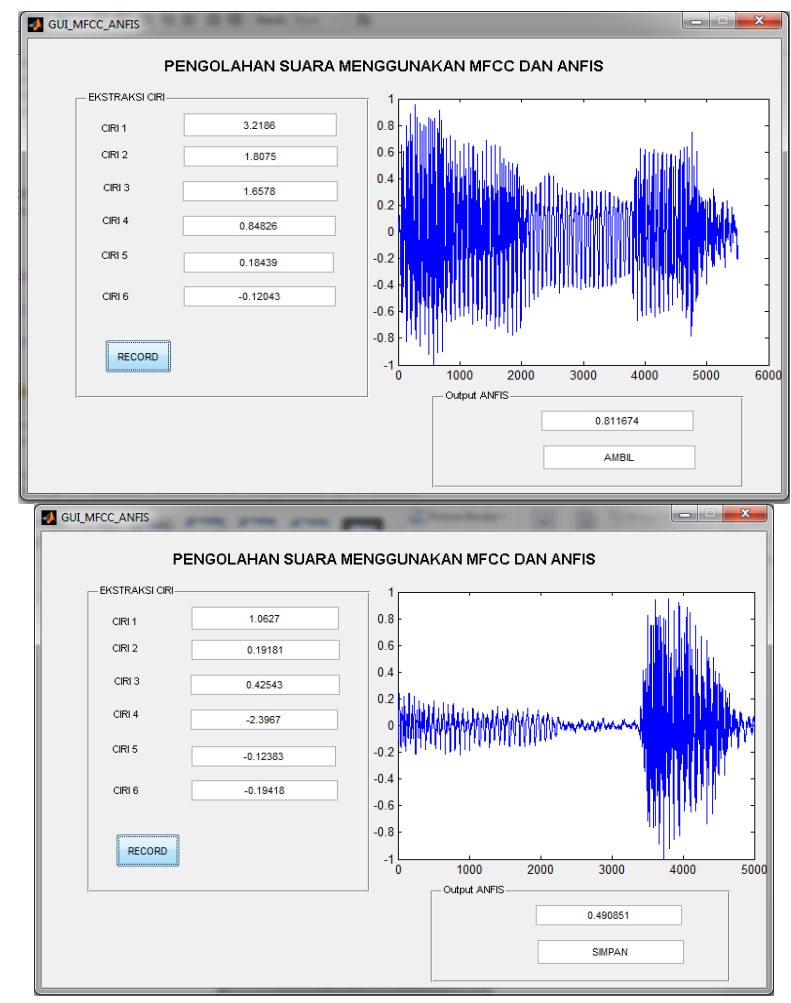

(a)

(b)

Gambar 11. Tampilan GUI MATLAB kontrol robot arm menggunakan perintah suara

\section{Simpulan}

Berdasarkan hasil penelitian diatas dapat disimpulkan hasil pengujian gerak sistem menunjukan bahwa sistem telah bekerja dengan baik sesuai dengan perintah yang diberikan. Dari 6. Ucapan Terima Kasih hasil pengujian sistem pengenal ucapan yang didapatkan penerapan metode MFCC dan ANFIS memiliki tingkat akurasi yang tinggi, yaitu $87,77 \%$ untuk responden yang terdapat dalam data latih (database) dan 78,53\% untuk responden diluar data latih (database).
Dalam pengujian untuk mengontrol robot arm 5 DoF memindahkan barang, sistem dapat bekerja dengan baik $100 \%$ melalui pembulatan nilai output hasil pengenalan pola suara.

Penelitian ini didanai oleh DIPA-BLU FST, UIN Sunan Gunung Djati Bandung. 


\section{Referensi}

[1] Thiang and S. Wijoyo, "Speech Recognition Using Linear Predictive Coding and Artificial Neural Network for Controlling Movement of Mobile Robot," International Conference on Information and Electronics Engineering, vol. 6, pp. 179-183, 2011.

[2] A. Rizal, L. Anggraeni and V. Suryani, "Pengenalan Suara ParuParu Normal Menggunakan LPC dan Jaringan Syaraf Tiruan BackPropagation," Proceeding EECCIS, 2006.

[3] B. Abinayaa, D. Arun, B. Darshini and C. Nataraj, "Voice Command Based Computer Application," International Journal of Innovative Research in Science, Engineering and Technology, vol. 4, no. 4, pp. 5763, 2015.

[4] G. Chauhan and P. Chaudhari, "Robotic Control using Speech Recognition and Android," International Journal of Engineering Research and General Science, vol. 3, no. 1, 2015.

[5] S. Tripathy, N. Baranwal and G. Nandi, "A MFCC based Hindi Speech Recognition Technique using HTK Toolkit," IEEE Second International Conference on Image Information Processing, pp. 539-544, 2013.

[6] B. A. Q. Al-Qatab and R. N. Ainon, "Arabic Speech Recognition Using Hidden Markov Model Toolkit(HTK)," IEEE, pp. 557-562,
2010.

[7] "Ekstrasi Ciri Suara Jantung menggunakan Metode Dekomposisi dan Korelasi Sinyal (Dekoriet) Berbasis Jaringan Saraf Tiruan," Jurnal Teori dan Aplikasi Fisika, vol. 3, no. 1, pp. 51-59, 2015.

8] Y.-m. Koo, G.-B. Kim, S.-C. Jang, W.-S. Lee, H.-G. Kim and S.-H. Han, "A Study on Travelling Control of Mobile Robot by Voice Commend," International Conference on Control, Automation and Systems, vol. 15, pp. 13-16, 2015.

[9] A. Punchihewa and Z. M. Arshad, "Voice Command Interpretation for Robot Control," International Conference on Automation, Robotics and Applications, vol. 5, pp. 90-95, 2011.

[10] B. Kulji, S. János and S. Tibor, "Mobile robot controlled by voice," International Symposium on Intelligent Systems and Informatics, vol. 5, pp. 189-192, 2007.

11] M. Varalakshmi and N. N. Raju, "Design of Speech Controlled Pick and Place Robot with Wireless Zigbee Technology," International Journal of Scientific Engineering and Technology Research, vol. 3, no. 20, pp. 4062-4066, 2014.

[12] K. S. Jadhav and S. M. Gaikwad, "Writing Robotic Arm by Speech Recognition," International Journal of Advanced Research in Electrical, Electronics and Instrumentation Engineering, vol. 4, no. 6, pp. 49834990, 2015.

[13] W. S. M. Sanjaya and Z. Salleh, "Implementasi Pengenalan Pola 
Suara Menggunakan Mel_Frequency Cepstrum Coefficients (MFCC) dan Adaptive Neuro-Fuzzy Inferense System (ANFIS) sebagai Kontrol Lampu Otomatis," Al-Hazen Journal of Physics, vol. 1, no. 1, pp. 44-54, 2014.

[14] D. Rudrapal, S. . D. Smita Das and N. D. N. Kar, "Voice Recognition and Authentication as a Proficient Biometric Tool and its Application in Online Exam for P.H People," International Journal of Computer Applications, vol. 39, no. 12, pp. 612, 2012.

[15] Srishti, P. Jain, Shalu and S. Singh, "Design and Development of Smart Wheelchair using Voice Recognition and Head Gesture Control System," International Journal of Advanced Research in Electrical, Electronics and Instrumentation Engineering, vol. 4, no. 5, pp. 4790-4798, 2015.

[16] C.-Y. Liu, T.-H. Hung, K.-C. Cheng and T.-H. S. Li, "HMM and BPNN based Speech Recognition System for Home Service Robot," International Conference on Advanced Robotics and Intelligent Systems, 2013.

[17] N. Rai and B. Rai, "An ANN Based Mobile Robot Control Through Voice Command Recognition Using Nepali Language," International
Journal of Applied Control, Electrical and Electronics Engineering (IJACEEE), vol. 2, no. 4, pp. 13-22, 2014.

[18] N. Srivastava, "Speech Recognition using Artificial Neural Network," International Journal of Engineering Science and Innovative Technology, vol. 3, no. 3, pp. 406-412, 2014.

[19] I. M. M. El-emary, M. Fezari and Hamz, "Hidden Markov model/Gaussian mixture models(HMM/GMM) based voice command system: A way to improve the control of remotely operated robot arm TR45," Scientific Research and Essays, vol. 6, no. 2, pp. 341350, 2011.

[20] R. Jang, C.-T. Sun and E. Mizutani, Neuro-Fuzzy and Soft Computing, Prentice-Hall, Inc., 1997. 